\title{
Synthesis, structures, and aromaticity of phosphole- containing porphyrins and their metal complexes
}

\section{$\operatorname{AUTHOR}(\mathrm{S})$ :}

Matano, Yoshihiro; Nakabuchi, Takashi; Imahori, Hiroshi

\section{CITATION:}

Matano, Yoshihiro ... [et al]. Synthesis, structures, and aromaticity of phosphole-containing porphyrins and their metal complexes. PURE AND APPLIED CHEMISTRY 2010, 82(3): 583593

ISSUE DATE:

2010

URL:

http://hdl.handle.net/2433/148436

RIGHT:

Copyright (c) 2009 International Union of Pure and Applied Chemistry 
Pure Appl. Chem., Vol. 82, No. 3, pp. 583-593, 2010.

doi:10.1351/PAC-CON-09-08-05

(C) 2010 IUPAC, Publication date (Web): 14 February 2010

\title{
Synthesis, structures, and aromaticity of phosphole-containing porphyrins and their metal complexes*
}

\author{
Yoshihiro Matano ${ }^{1, \ddagger}$, Takashi Nakabuchi $^{1}$, and Hiroshi Imahori ${ }^{1,2,3}$ \\ ${ }^{1}$ Department of Molecular Engineering, Graduate School of Engineering, Kyoto \\ University, Nishikyo-ku, Kyoto 615-8510, Japan; ${ }^{2}$ Institute for Integrated Cell- \\ Material Sciences (iCeMS), Kyoto University, Nishikyo-ku, Kyoto 615-8510, Japan; \\ ${ }^{3}$ Fukui Institute for Fundamental Chemistry, Kyoto University, Sakyo-ku, \\ Kyoto 606-8103, Japan
}

\begin{abstract}
Our recent studies on the synthesis, structures, and aromaticity of phosphole-containing porphyrins and their metal complexes are summarized. Core-modified $\mathrm{P}, \mathrm{X}, \mathrm{N}_{2}$-porphyrins $(X=S, N)$ are accessible from a $\sigma^{4}$-phosphatripyrrane and the corresponding 2,5-difunctionalized heteroles in a few steps. X-ray structural analysis of the $\sigma^{3}-\mathrm{P}, \mathrm{N}_{3}$ porphyrin revealed that it possesses a slightly distorted $18 \pi$ plane. The phosphorus atom incorporated at the core plays an important role in producing unprecedented reactivity and coordinating ability for the porphyrin ring. The $\mathrm{P}_{3} \mathrm{~N}_{3}$ free base reacts with $\left[\mathrm{RhCl}(\mathrm{CO})_{2}\right]_{2}$ in dichloromethane, ultimately yielding an $18 \pi \mathrm{P}, \mathrm{N}_{3}$-rhodium(III) complex, whereas the P,S, $\mathrm{N}_{2}$ free base undergoes redox-coupled complexation with zero valent group 10 metals to afford the corresponding P,S, $\mathrm{N}_{2}$-isophlorin-metal(II) complexes. The aromaticity of the free-base porphyrins and the metal complexes was uncovered based on both experimental and theoretical results. It is of particular interest that the $\mathrm{P}, \mathrm{S}, \mathrm{N}_{2}$-isophlorin-metal complexes exhibit only a weak antiaromaticity in terms of the magnetic criterion.
\end{abstract}

Keywords: aromaticity; coordination; core-modification; phosphole; porphyrin.

\section{INTRODUCTION}

Core-modification is an indispensable method for altering the optical, electrochemical, and coordinating properties as well as the reactivity of a porphyrin $\pi$-system, and many examples have been reported for carbon- or chalcogen-modified derivatives [1]. The incorporation of a phosphorus atom at the core is also a promising strategy for developing new areas of porphyrin-based coordination and materials chemistry, because the phosphole subunit behaves both as a neutral P ligand and as a highly conjugative 1,3-dienic $\pi$-system [2]. Until recently, however, phosphole-containing porphyrins (phosphaporphyrins) have not been addressed in the literature [3,4], probably due to the limited access to their potential precursors. Recently, we established a convenient method for the synthesis of various 2,5-difunctionalized phospholes via titanacycle intermediates [5]. This enabled us to obtain the first examples of the phosphole-containing porphyrin family of the $\mathrm{P}, \mathrm{X}, \mathrm{N}_{2}$-type [6-8]. It has been clarified that this class of compounds exhibits unprecedented coordination behavior as mixed-donor macrocyclic ligands.

\footnotetext{
*Paper based on a presentation at the $9^{\text {th }}$ International Conference on Heteroatom Chemistry (ICHAC-9), 30 June-4 July 2009 , Oviedo, Spain. Other presentations are published in this issue, pp. 505-677.

¥Corresponding author
} 
Our studies concerning the synthesis and coordination chemistry of the phosphole-containing porphyrin family were overviewed in a recent account [1j]. Herein we particularly focus on the phosphaporphyrins and their metal complexes, and describe their structures and aromaticity in detail.

\section{SYNTHESIS OF PHOSPHAPORPHYRINS}

The phosphole-containing hybrid porphyrins (denoted hereafter as $\mathrm{P}, \mathrm{X}, \mathrm{N}_{2}$-porphyrins) $\mathbf{4 X}(\mathbf{X}=\mathbf{N}, \mathbf{S})$ were successfully synthesized from P-masked phosphatripyrrane $\mathbf{1}$ and 2,5-difunctionalized heteroles $\mathbf{2 X}(\mathbf{X}=\mathbf{N}, \mathbf{S})[9,10]$ by three-step sequential reactions (Scheme 1) [6]: (i) $\mathrm{BF}_{3}$-promoted dehydrative condensation of $\mathbf{1}$ with $\mathbf{2 X}$, (ii) desulfurization at the phosphorus center of $\mathbf{3 X}-\mathbf{S}(\mathbf{X}=\mathbf{N}, \mathbf{S})$ with $\mathrm{P}\left(\mathrm{NMe}_{2}\right)_{3}$, and (iii) ring oxidation of $\sigma^{3}$-porphyrinogens $\mathbf{3 X}(\mathbf{X}=\mathbf{N}, \mathbf{S})$ with 2,3-dichloro-5,6-dicyanobenzoquinone (DDQ). During the ring oxidation from $\mathbf{3 X}$ to $\mathbf{4 X}$ side reactions took place probably via P-oxidation (vide infra). The target $\mathrm{P}, \mathrm{X}, \mathrm{N}_{2}$-porphyrins $\mathbf{4 N}$ and $\mathbf{4 S}$ were isolated as reddish purple solids after column chromatography on alumina, and their structures were fully characterized by spectroscopy and X-ray crystallography (vide infra). In an attempt to synthesize a TPP-type phosphaporphyrin (TPP $=5,10,15,20$-tetraphenylporphyrin) based on a different [3+1] approach, Mathey and co-workers isolated a small amount of "P-confused" carbaporphyrinoid instead of normal phosphaporphyrin [4]. These results indicate that a suitable choice of precursors is of utmost importance in promoting the desired porphyrin-ring formation.

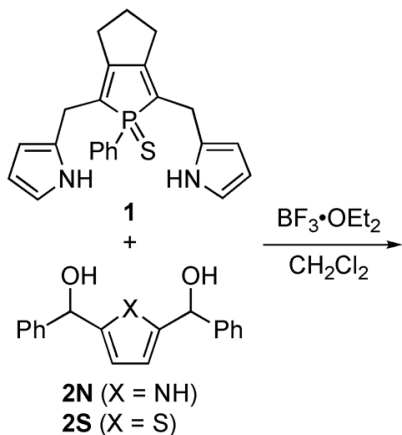

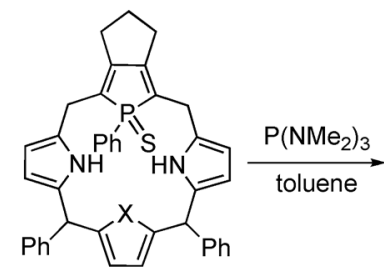

$3 \mathrm{~N}-\mathrm{S}(\mathrm{X}=\mathrm{NH} ; 43 \%)$ 3S-S $(X=S ; 36 \%)$

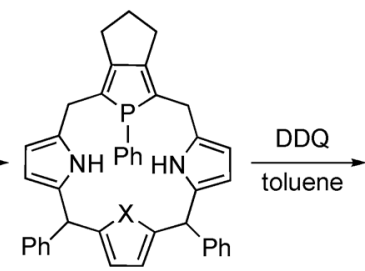

$3 \mathrm{~N}(\mathrm{X}=\mathrm{NH} ; 95 \%)$ $3 \mathrm{~S}(\mathrm{X}=\mathrm{S} ; 93 \%)$

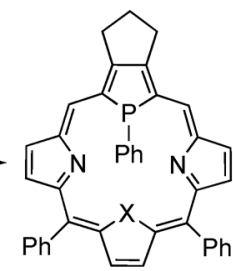

4N $(X=\mathrm{NH} ; 17 \%)$ $4 \mathrm{~S}(\mathrm{X}=\mathrm{S} ; 5 \%)$

Scheme 1 Synthesis of $P, X, N_{2}$-porphyrins.

The $\mathrm{P}, \mathrm{X}, \mathrm{N}_{2}$-porphyrins $\mathbf{4 X}$ exhibit unique reactivities depending on the heteroatom (X) (Scheme 2). On treatment with $\mathrm{H}_{2} \mathrm{O}_{2}$, the $18 \pi \sigma^{3}-\mathrm{P}, \mathrm{X}, \mathrm{N}_{2}$-porphyrins $\mathbf{4 N}$ and $\mathbf{4 S}$ were gradually transformed into $22 \pi \sigma^{4}-\mathrm{P}, \mathrm{N}_{3}$-porphyrin $\mathbf{6}$ and $20 \pi \sigma^{4}$-P,S, $\mathrm{N}_{2}$-porphyrin 7 , respectively, as major isolable products $[6 \mathrm{~b}, \mathrm{c}]$. These reactions are probably initiated by oxygenation at the phosphorus center, though intermediates $\mathbf{5 X}$ could not be isolated due to their instability. The major route for the second step for $\mathbf{5 N}$ is dehydrogenation of the fused five-membered ring, whereas that for $\mathbf{5 S}$ is hydrogenation of the macrocycle. The completely different behavior observed for $\mathbf{4 N}$ and $\mathbf{4 S}$ demonstrates that the combination of core heteroatoms plays a crucial role in determining reaction courses for the phosphole-containing porphyrin $\pi$-systems. 


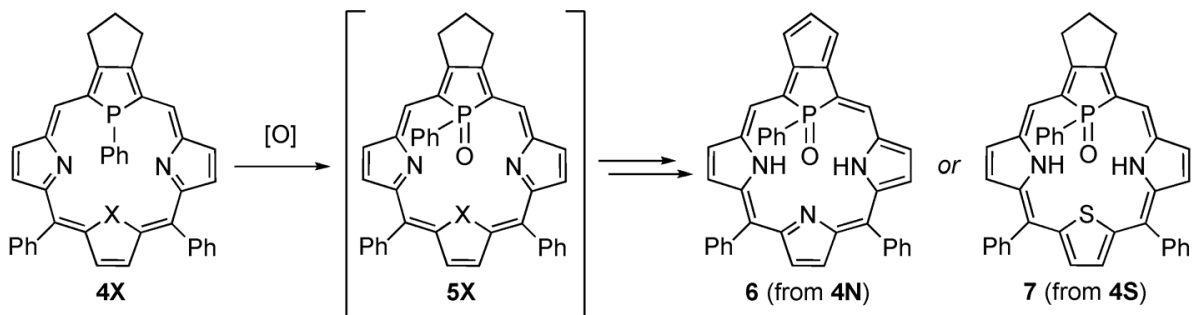

Scheme 2 P-oxidation reactions of $\mathrm{P}, \mathrm{X}, \mathrm{N}_{2}$-porphyrins.

\section{COMPLEXATION WITH TRANSITION METALS}

With $\mathrm{P}, \mathrm{X}, \mathrm{N}_{2}$ free bases $\mathbf{4 X}$ in hand, we examined their complexation reactions with late transition metals. As shown in Scheme 3, treatment of the $\sigma^{3}-\mathrm{P}, \mathrm{N}_{3}$-porphyrin $4 \mathbf{N}$ with $\left[\mathrm{RhCl}(\mathrm{CO})_{2}\right]_{2}$ in $\mathrm{CH}_{2} \mathrm{Cl}_{2}$ at room temperature gave Rh-P, $\mathrm{N}_{3}$ complex 8 as a sole isolable product [11]. During this complexation, $\mathrm{Rh}(\mathrm{I})$ is oxidized to $\mathrm{Rh}(\mathrm{III})$, and the $\mathrm{P}, \mathrm{N}_{3}$ platform behaves as a monoanionic ligand while keeping the $18 \pi$ circuit. The $\sigma^{3}-\mathrm{P}, \mathrm{S}, \mathrm{N}_{2}$-porphyrin $\mathbf{4 S}$ reacted with $\mathrm{Pd}(\mathrm{dba})_{2}$ to produce $\mathrm{Pd}-\mathrm{P}, \mathrm{S}, \mathrm{N}_{2}$ complex $\mathbf{9 P d}$ in quantitative yield within a few minutes at room temperature (Scheme 3), while no complexation took

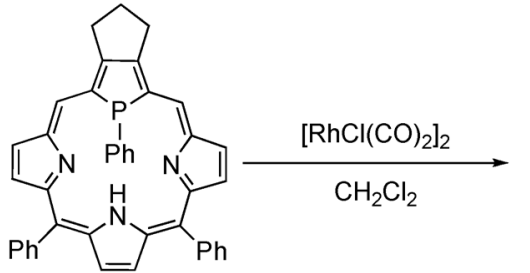

$4 \mathbf{N}$

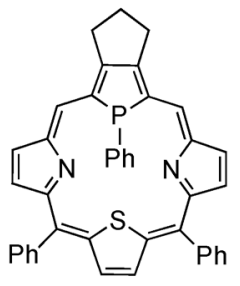

d) $)_{2} / \mathrm{CH}_{2} \mathrm{Cl}_{2}$ $\mathrm{Pd}(\mathrm{dba})_{2} / \mathrm{CH}_{2} \mathrm{Cl}_{2}$ $\mathrm{Pt}(\mathrm{dba})_{2} / 1,2-\mathrm{Cl}_{2} \mathrm{C}_{6} \mathrm{H}_{4}$<smiles>c1ccccc1</smiles>

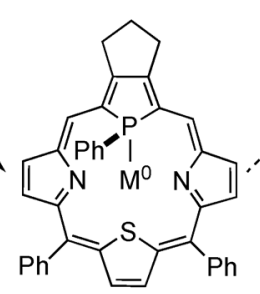<smiles></smiles>

10
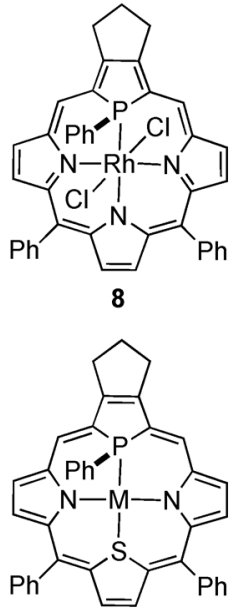

$9 \mathrm{Ni}(\mathrm{M}=\mathrm{Ni})$

9Pd $(\mathrm{M}=\mathrm{Pd})$

9Pt ( $M=P t)$

metal-to-ligand

electron transfer

Scheme 3 Complexation of $\mathrm{P}, \mathrm{X}, \mathrm{N}_{2}$-porphyrins $\mathbf{4 X}$. 
place between $\mathrm{S}_{2}, \mathrm{~N}_{2}$-porphyrin 10 and $\mathrm{Pd}(\mathrm{dba})_{2}$ even after refluxing in 1,2-dichlorobenzene for $5 \mathrm{~h}$ [12]. The theoretical studies (density functional theory, DFT, calculations) on model compounds support the observed results; the palladium complexation with a model of $\mathbf{4 S}$ is thermodynamically favorable, whereas that with a model of $\mathbf{1 0}$ is unfavorable. These results show that the core-phosphorus atom in $\mathbf{4 S}$ contributes significantly to the facile complexation with palladium.

Both experimental and theoretical studies indicate that the oxidation states of the palladium center and the macrocyclic $\mathrm{P}, \mathrm{S}, \mathrm{N}_{2}$ ligand in $\mathbf{9 P d}$ are +2 and -2 , respectively. It is therefore likely that the redox-coupled complexation, namely, simultaneous or stepwise processes including P-to-metal coordination and metal-to-ligand electron transfer, occurs in the reaction between $\mathbf{4 S}$ and the zero valent palladium. When $\mathrm{Ni}(\mathrm{cod})_{2}$ or $\mathrm{Pt}(\mathrm{dba})_{2}$ was used in place of $\mathrm{Pd}(\mathrm{dba})_{2}$, a similar reaction occurred to produce Ni-P,S, $\mathrm{N}_{2}$ complex 9Ni and Pt-P,S, $\mathrm{N}_{2}$ complex 9Pt, respectively [12]. Complexes $9 \mathrm{M}$ have a dianionic $20 \pi \mathrm{P}, \mathrm{S}, \mathrm{N}_{2}$-porphyrin ( $\mathrm{P}, \mathrm{S}, \mathrm{N}_{2}$-isophlorin) ligand, and are the first examples of air stable coremodified isophlorin-metal complexes.

\section{CRYSTAL STRUCTURES}

Figure 1 depicts the structures of $\mathbf{4 N}, \mathbf{6}, \mathbf{8}$, and $\mathbf{9 P d}[6 \mathrm{~b}, \mathrm{c}, 11,12]$. The deviation parameters, which are distances of the 24 atoms from the 24 -atom mean plane, and interatomic distances between the two facing core heteroatoms are also included.

In all compounds, the P-phenyl group is located above the $\pi$ plane, which exemplifies typical geometry of the $\sigma^{3}$ (trigonal pyramidal) and $\sigma^{4}$ (tetrahedral) phosphorus centers. The shape and the deviation from planarity of the porphyrin $\pi$ plane are strongly dependent on the geometry of the phosphorus atom as well as on the components of the $\pi$-systems. The $18 \pi \sigma^{3}-\mathrm{P}, \mathrm{N}_{3}$-porphyrin $4 \mathbf{N}$ possesses a slightly distorted $18 \pi$ plane, wherein the phosphole and three pyrrole rings are somewhat tilted from the 24-atom mean plane (Fig. 1a) [6b]. It seems likely that the porphyrin $18 \pi$ circuit does not involve the lone electron pair of the $\sigma^{3}$-P atom. On the contrary, the $22 \pi \sigma^{4}-\mathrm{P}, \mathrm{N}_{3}$-porphyrin 6 has a highly ruffled structure, where the phosphorus atom is deviated significantly from the porphyrin $\pi$ plane $(1.20 \AA$ for 6 vs. $0.34 \AA$ for $\mathbf{4 N}$ ) to avoid the steric congestion at the core (Fig. 1b) [6b]. Accordingly, the $\mathrm{P} \cdots \mathrm{N}_{23}$ distance of $\mathbf{6}$ is considerably lengthened as compared with that of $\mathbf{4 N}$. In addition, inclinations of $\mathrm{N}_{22^{-}}$and $\mathrm{N}_{24}$-containing pyrrole rings from the mean $\pi$ plane of $\mathbf{6}$ are larger than those of $\mathbf{4 N}$. The observed distance between the oxygen and nitrogen atoms $\left(\mathrm{O} \cdots \mathrm{N}_{22}\right.$ and $\mathrm{O} \cdots \mathrm{N}_{24}$, each $2.65 \AA$ ) suggests that the unusual $22 \pi$ network is stabilized through the intramolecular $\mathrm{P}-\mathrm{O} \cdots \mathrm{H}-\mathrm{N}$ hydrogen-bonding interaction. It has been elucidated that the $20 \pi \sigma^{4}-\mathrm{P}, \mathrm{S}, \mathrm{N}_{2}$-porphyrin 7 is also stabilized by a similar interaction [6c]. Figure $1 \mathrm{c}$ depicts the crystal structure of $\mathbf{8}$, in which the $\mathrm{Rh}(\mathrm{III})$ center adopts an octahedral geometry with two chlorine atoms above and below the $\pi$ plane [11]. It should be noted that the phosphorus and three nitrogen atoms are almost on the same plane. The $\mathrm{P}, \mathrm{N}_{3}$-porphyrin platform is more distorted than that of $\mathbf{4 N}$, which is reflected in the deviation parameters at the phosphorus atom $(0.75 \AA$ for $\mathbf{8}$ vs. $0.34 \AA$ for $\mathbf{4 N})$ and the elongation of the P $\cdots \mathrm{N}_{23}$ distance from 3.45 to $4.22 \AA$. As shown in Fig. 1d, the palladium center of 9Pd adopts a square planar geometry coordinated by four core heteroatoms, and the phosphorus and sulfur atoms are displaced largely from the mean $\pi$ plane comprised of the 24 atoms [12]. In this complex, the phosphorus and sulfur atoms are deviated toward opposite directions ( $0.89 \AA$ for $\mathrm{P}$ and $-0.88 \AA$ for $\mathrm{S})$ against the mean $\pi$ plane. Importantly, the $\mathrm{P}, \mathrm{X}, \mathrm{N}_{2}$-hybrid ligands change their shapes to bind metals under the most suitable coordination environments at the core. The peripheral carbon-carbon bond alternation (not shown here) of these phosphole-containing porphyrins implies the significant contribution of $18 \pi(\mathbf{4 N}$ and 8$), 20 \pi(7$ and $9 P d)$, or $22 \pi(6)$ annulene circuits depicted in Schemes 1-3. With this structural information in hand, a few fundamental questions arise. Are they aromatic, antiaromatic, or nonaromatic? How large is the aromaticity of each compound? Which factors determine the aromaticity of this class of compounds? These issues are discussed in the following section. 
(a)

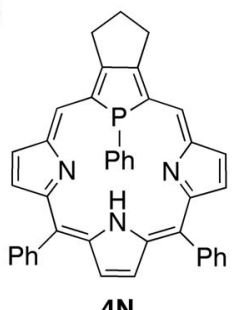

(b)

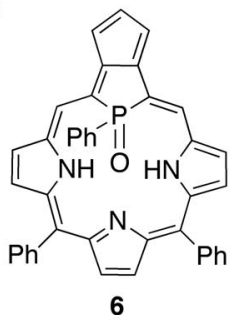

(c)

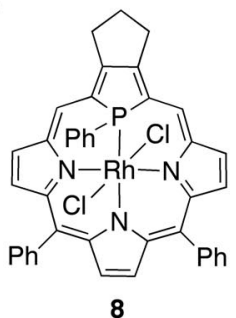

(d)

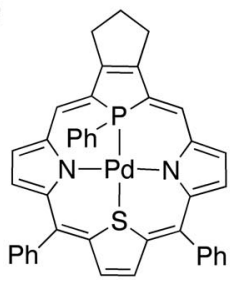

9Pd
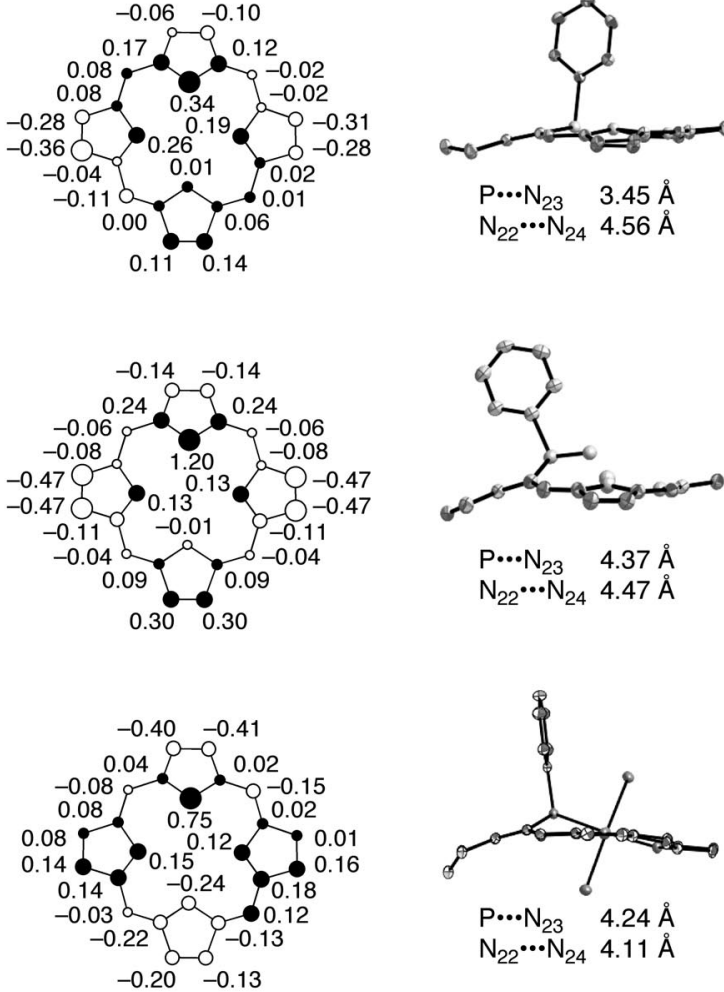

$\mathrm{P} \cdot \cdots \mathrm{N}_{23} \quad 3.45 \AA$

$\mathrm{N}_{22} \cdots \mathrm{N}_{24} 4.56 \AA$

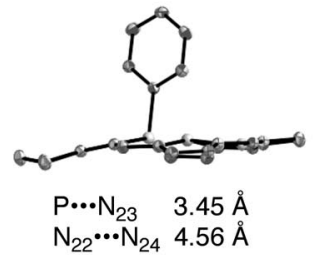

$\mathrm{N}_{22} \cdots \mathrm{N}_{24} 4.11 \AA$
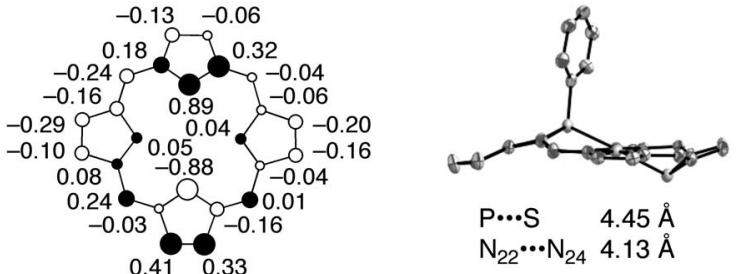

$$
\begin{aligned}
& \text { - } \bigcirc>0.30 \AA \\
& \text { - } 0.10-0.30 \AA \\
& \text { - } \circ<0.10 \AA
\end{aligned}
$$

Fig. 1 Side views and deviations of (a) 4N, (b) 6, (c) 8, and (d) 9Pd. In the side views, hydrogen atoms (except for $\mathrm{NH}$ ) and meso-phenyl groups are omitted for clarity. The values in the middle column are distances (in $\AA$ ) of the 24 atoms from the 24-atom mean plane. Solid circles and open circles indicate directions of the deviation (plus and minus) from the mean plane.

\section{AROMATICITY}

Aromaticity has long been the subject of numerous studies in porphyrin chemistry, because it depends on a variety of factors such as ring size, peripheral substituents, central metals, and core elements. In this context, the aromaticity is a key index for characterizing the porphyrin $\pi$-systems, and has been generally evaluated in terms of energetic (resonance stabilization), structural (bond length alternation, planarity), and magnetic (ring current effects) criteria. Among them, the magnetic ring current effects 
of the $\pi$ circuit are experimentally observable as unusually shielded or deshielded chemical shifts of the inner and outer (peripheral) protons, and are theoretically predictable as nucleus-independent chemical shifts (NICS) or ring-current densities [13]. Based on the observed and calculated data, the effects of core elements, $\pi$-conjugation modes, and central metals on the aromaticity are discussed briefly.

To evaluate diatropic and paratropic ring current effects quantitatively, $\mathrm{P}, \mathrm{X}, \mathrm{N}_{2}$-calixphyrins $11 \mathrm{X}$ $(\mathbf{X}=\mathbf{N}, \mathbf{S}), \mathbf{1 2}$, and 13, wherein the $\pi$-circuits are disrupted at two $\mathrm{sp}^{3}$ meso carbons, are used as references [7]. That is, upfield/downfield shifts $(\Delta \delta)$ of the heterole- $\beta$ (peripheral) protons and P-phenyl ortho/metalpara protons of $\mathbf{4 X}, \mathbf{8}$, and $\mathbf{9 P d}$ from the corresponding protons of $\mathbf{1 1 X}, \mathbf{1 2}$, and $\mathbf{1 3}$ (Fig. 2) represent the character of the aromaticity, and the absolute values of $\Delta \delta$ reflect the degree of the ring current effects.

(a)

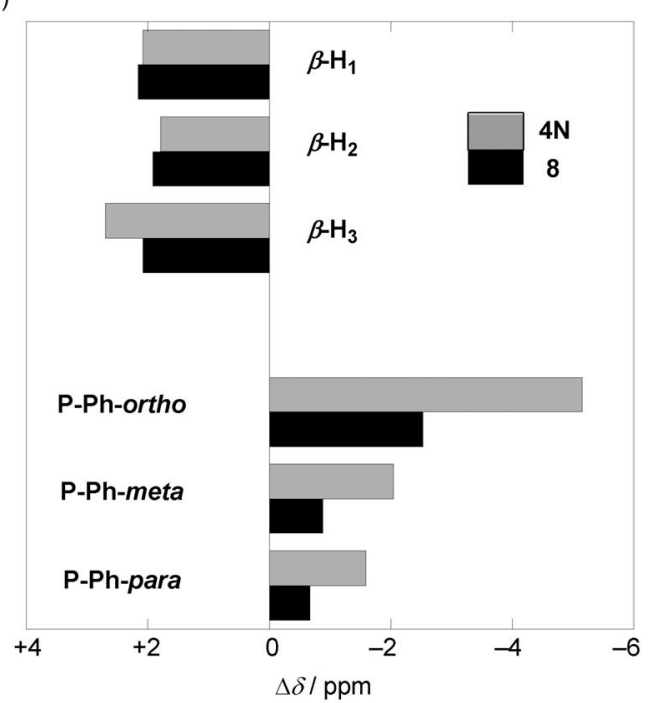

(b)

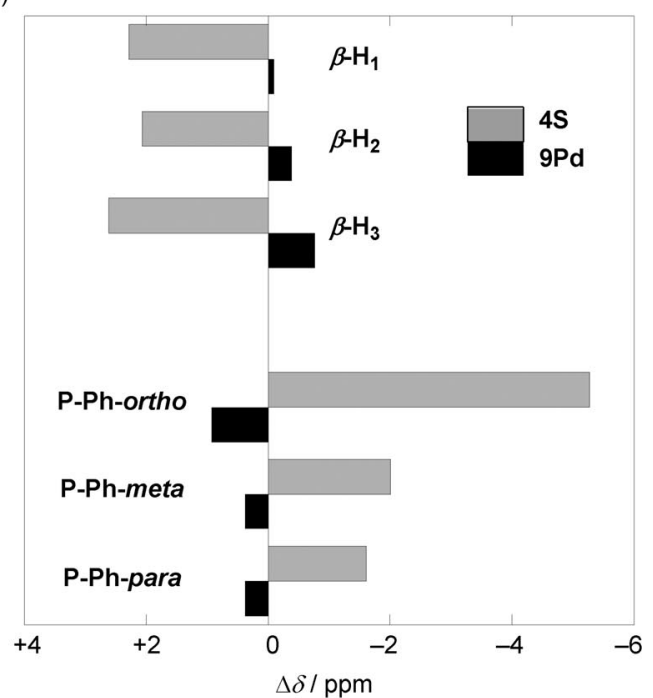

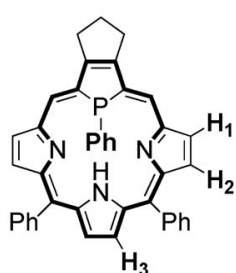

$4 \mathrm{~N}$
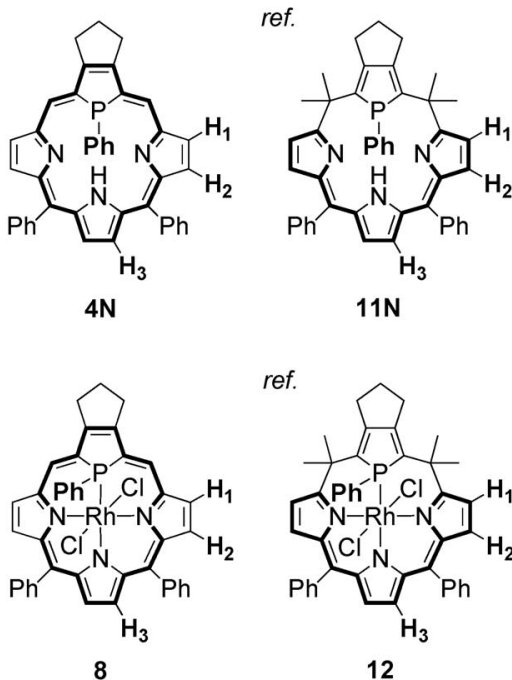

12

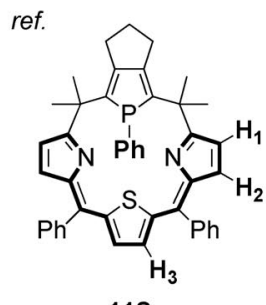

$11 \mathrm{~S}$

ref.

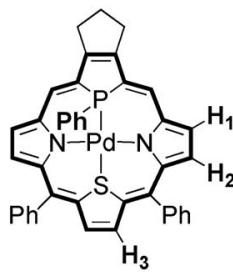

9Pd

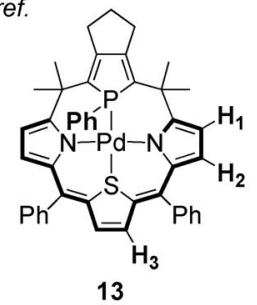

Fig. 2 Upfield/downfield shifts $\left(\Delta \delta\right.$ ) of the $\beta$ and P-phenyl protons of (a) $\mathrm{P}, \mathrm{N}_{3}$ derivatives $\mathbf{4 N}$ and 8 from those of $11 \mathrm{~N}$ and 12, and (b) P,S, $\mathrm{N}_{2}$ derivatives $4 \mathrm{~S}$ and $9 \mathrm{Pd}$ from those of $11 \mathrm{~S}$ and 13. 
In the ${ }^{1} \mathrm{H}$ NMR spectra of the free bases, the heterole- $\beta$ protons of $\mathbf{4 X}$ are deshielded as compared with the corresponding protons of calixphyrins $\mathbf{1 1 X}$, whereas the P-phenyl protons as well as the $\mathrm{NH}$ proton $(\mathbf{4 N})$ are shielded relative to those of $11 \mathbf{X}$ [6,7]. Obviously, the significant downfield and upfield shifts stem from large diatropic ring current effects of the porphyrin $18 \pi$ circuit in $\mathbf{4 X}$. The degree of shielding effects on the P-phenyl-ortho, -meta, and -para protons decreases in this order (Fig. 2), indicating that the P-phenyl group is located above the $18 \pi$ plane. It is noteworthy that the core modification with phosphorus provides additional information about the ring current effects, as the ${ }^{31} \mathrm{P}$ nucleus is NMR active. Indeed, the ${ }^{31} \mathrm{P}$ peaks of porphyrins $\mathbf{4 N}(\delta 5.2)$ and $\mathbf{4 S}(\delta 18.6)$ are very deshielded relative to the respective peaks of calixphyrins $11 \mathrm{~N}(\delta 24.0)$ and $\mathbf{1 1 S}(\delta 26.7)$. The Rh-P,N $\mathrm{N}_{3}$ complex 8 also shows diatropic ring current effects in its ${ }^{1} \mathrm{H}$ NMR spectrum (Fig. 2a) [11], although the shielding effect on the P-phenyl group is somewhat smaller than that observed for the free base $\mathbf{4 N}$. This is ascribable to the difference in relative conformation of the phosphole- $18 \pi$ planes between 8 and $4 \mathbf{N}$ (vide supra). In sharp contrast to $\mathbf{8}$, the $\mathrm{M}-\mathrm{P}, \mathrm{S}, \mathrm{N}_{2}$ complexes $\mathbf{9 M}$ display very weak paratropic ring current effects on their NMR chemical shifts (Fig. 2b) [12]. For example, the peripheral and P-phenyl protons of 9Pd are slightly shielded and deshielded, respectively, as compared with those of $\mathbf{1 3}$. These observations indicate that the $20 \pi \mathrm{P}, \mathrm{S}, \mathrm{N}_{2}$ circuit of $\mathbf{9 M}$ contains only a little antiaromatic character in terms of the magnetic criterion. As indicated by no detectable change in the spectral pattern and chemical shifts in the temperature range from -50 to $50{ }^{\circ} \mathrm{C}$, the $20 \pi$-system in $9 \mathrm{M}$ is sufficiently rigid and does not undergo rapid $\pi$-bond shift in solution.

The NICS values $($ negative $=$ aromatic; positive $=$ antiaromatic; zero $=$ nonaromatic) calculated for model compounds (Fig. 3) basically support the above-mentioned NMR spectral features. The degree of aromaticity is reflected in absolute NICS values; the more negative or more positive the NICS values are, the more aromatic or more antiaromatic the $\pi$ circuits are. As listed in Fig. 3, the NICS values at positions $a$ and $b$ in the $\mathrm{P}, \mathrm{X}, \mathrm{N}_{2}$ models $\mathbf{4 X}-\mathbf{m}$ are indicative of a fully aromatic character, although they are not as negative as the corresponding values of the parent $\mathrm{N}_{4}$-porphyrin and the $\mathrm{S}_{2}, \mathrm{~N}_{2}$ model 10-m [6,13a]. The small, negative NICS values calculated for $\mathbf{9 P d}-\mathbf{m}$ may support the experimentally observed results; the $20 \pi \mathrm{P}, \mathrm{S}, \mathrm{N}_{2}$-isophlorin ring in $\mathbf{9 P d}-\mathbf{m}$ contains very weak antiaromaticity based on the DFT results. To rationalize the loss of paratropicity observed and calculated for the isophlorin complexes 9M, at least three factors should be taken into consideration; (i) the electronic effects of core elements, (ii) the electronic effects of central metals, and (iii) the deviation from planarity of $\pi$ circuits [14]. To evaluate these factors, NICS values of $\mathrm{Pd}-\mathrm{S}_{2}, \mathrm{~N}_{2}$ and $\mathrm{Mg}-\mathrm{P}, \mathrm{S}, \mathrm{N}_{2}$ model complexes $\left(\mathbf{P d}-\mathbf{S}_{\mathbf{2}}, \mathbf{N}_{\mathbf{2}}-\mathbf{m}\right.$ and $\left.\mathbf{9 M g}-\mathbf{m}\right)$ were also calculated as references [12]. At the optimized structure, NICS values of $\mathbf{P d}-\mathbf{S}_{\mathbf{2}}, \mathbf{N}_{\mathbf{2}}-\mathbf{m}$ are close to those of $\mathbf{9 P d}-\mathbf{m}$, implying that the replacement of phosphorus with sulfur does not alter the ring current effects much. This is probably due to the similarity of these two heteroatoms in terms of the electron number and covalent bond radii. On the other hand, $\mathbf{9 M g}-\mathbf{m}$ displays rather positive NICS values of +2.66 and +3.03 , despite the fact that the optimized geometry of its $\pi$-system is similar to that of $\mathbf{9 P d - m}$. It is therefore likely that the lack of paratropic ring currents in 9M-m stems partially from the electronic nature of the central group 10 metals.

Care must be taken to quantitatively evaluate the third factor, deviation from planarity, as the shape, the size, and the rigidity (flexibility) of $4 n \pi$-systems should all be considered when interpreting the paratropism of $[4 n]$ annulenes. In the pioneering studies on the structure-property relationship of core-modified isophlorins, Vogel and co-workers exemplified conformation-induced loss of paratropism in a saddle-shaped tetra- $N$-methyl $\beta$-octaethylporphyrin $\left(\mathrm{N}_{4}\right.$-isophlorin) [15]. Chen's $\beta$-tetrakis(trifluoromethyl)-meso-tetraphenylporphyrin also adopts a highly distorted saddle conformation and shows almost complete conformation-induced loss of paratropicity in the $20 \pi$ isophlorin system [16]. By contrast, Setsune's $N^{21}, N^{22}$-bridged $\mathrm{N}_{4}$-isophlorins are not highly deviated from planarity and exhibit paratropic ring current effects in the ${ }^{1} \mathrm{H}$ NMR spectra [17]. Anand's core-modified $\mathrm{O}_{4^{-}}$and $\mathrm{O}_{2}, \mathrm{~S}_{2}$-isophlorins bearing meso-pentafluorophenyl groups have a completely planar structure and display antiaromatic character [18]. In addition to these isophlorin free bases, a few TPP-type metal- $\mathrm{N}_{4^{-}}$ 

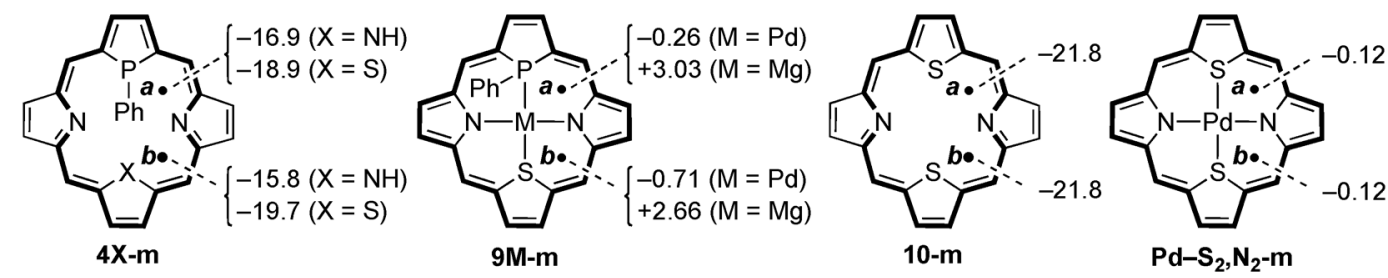

Fig. 3 NICS (in ppm) at the center $(a, b)$ of two adjacent heterole rings of $\mathbf{4 X}-\mathbf{m}, \mathbf{9 M}-\mathbf{m}, \mathbf{1 0}-\mathbf{m}$, and $\mathbf{P d}-\mathbf{S}_{2}, \mathbf{N}_{\mathbf{2}}-\mathbf{m}$. The NICS values were calculated with the GIAO-RHF method at the DFT-optimized geometries [GIAO-RHF/ 6-31+G(d)//B3LYP/6-311G(d,p)]. For details, see ref. [6].

isophlorin complexes have recently been characterized by spectroscopy and/or X-ray crystallography $[19,20]$. Interestingly, Vaid's silicon(IV)- and germanium(IV)- $\mathrm{N}_{4}$-isophlorin complexes display significant antiaromatic character, despite having highly ruffled $20 \pi$-systems [19]. These studies have revealed some intrinsic factors controlling the paratropicity of isophlorin derivatives. However, the number of structurally characterized examples is quite limited, and the effects of other factors such as the highest occupied molecular orbital-lowest unoccupied molecular orbital (HOMO-LUMO) gap and heavy-atom effects should also be investigated. In this regard, understanding of the structure-aromaticity relationship of this unusual $20 \pi$-system is still a challenging task from both experimental and theoretical points of view.

\section{OPTICAL AND ELECTROCHEMICAL PROPERTIES}

The optical and electrochemical properties of porphyrin derivatives are closely related to the electronic structures as well as the aromatic characters of their $\pi$ circuits. In this section, the absorption and redox properties of some $\mathrm{P}, \mathrm{X}, \mathrm{N}_{2}$ porphyrin derivatives are compared with each other. In the UV-vis absorption spectra of the $18 \pi \sigma^{3}-\mathrm{P}, \mathrm{X}, \mathrm{N}_{2}$-porphyrins $\mathbf{4 X}$, the characteristic two transitions, B (Soret) and $\mathrm{Q}$ bands, are clearly observed, wherein the lowest-energy $\mathrm{Q}$ band reaches the near infrared region $(700-800 \mathrm{~nm})$ [6]. The Soret bands of $\mathbf{4 N}\left(\lambda_{\max } 431 \mathrm{~nm}\right)$ and $\mathbf{4 S}\left(\lambda_{\max } 440 \mathrm{~nm}\right)$ are red-shifted relative to those of TPP $\left(\lambda_{\max } 411 \mathrm{~nm}\right)$ [21] and $\mathrm{S}_{2}, \mathrm{~N}_{2}$ reference $\mathbf{1 0}\left(\lambda_{\max } 426 \mathrm{~nm}\right)$. These results show that the incorporation of a phosphorus atom considerably reduces both the $S_{0}-S_{2}$ and $S_{0}-S_{1}$ excitation energies. The $18 \pi \mathrm{Rh}-\mathrm{P}, \mathrm{N}_{3}$ complex 8 also shows characteristic Soret and Q bands, whereas the $20 \pi$ $\mathrm{Pd}-\mathrm{P}, \mathrm{S}, \mathrm{N}_{2}$-isophlorin complex 9Pd displays broad and blue-shifted Soret-like bands and no detectable $\mathrm{Q}$ bands, which is typical of highly ruffled, nonaromatic $4 n \pi$ porphyrinoids [22].

As shown in Fig. 4 (for $\mathbf{4 S}$ ), the electrochemical oxidation of $18 \pi \mathrm{P}, \mathrm{X}, \mathrm{N}_{2}$-porphyrins $\mathbf{4 X}$ proceeds irreversibly, whereas the reduction proceeds reversibly in cyclic voltammetry [6]. The first oxidation and reduction potentials $\left(E_{\mathrm{ox}}\right.$ and $E_{\text {red }}$ relative to $\mathrm{Fc} / \mathrm{Fc}^{+}$couple) of $4 \mathrm{~N}\left(E_{\mathrm{ox}}=+0.38 \mathrm{~V} ; E_{\mathrm{red}}=-1.51 \mathrm{~V}\right)$ are shifted to the negative and positive sides, respectively, as compared with those of TPP $\left(E_{\mathrm{Ox}}=\right.$ $+0.58 \mathrm{~V} ; E_{\text {red }}=-1.73 \mathrm{~V}$ ) [21]. It is evident that the incorporation of a phosphorus atom raises the HOMO level, lowers the LUMO level, and, as a consequence, narrows the HOMO-LUMO gap of the porphyrin $\pi$-system. Further incorporation of the sulfur atom (from $4 \mathbf{N}$ to $4 S$ ) induces positive shifts of both $E_{\mathrm{Ox}}$ and $E_{\text {red }}\left(E_{\mathrm{OX}}=+0.45 \mathrm{~V} ; E_{\text {red }}=-1.36 \mathrm{~V}\right)$. In contrast to $4 \mathrm{~S}, \mathrm{Pd}-$ and Pt-P,S,N $\mathrm{N}_{2}$ complexes $9 \mathrm{Pd}$ and $9 \mathrm{Pt}$ show reversible oxidation processes in the considerably negative region $\left(E_{\mathrm{ox}}=-0.26 \mathrm{~V} ; E_{\text {red }}=\right.$ $-2.07 \mathrm{~V}$ for $9 \mathrm{Pd}, E_{\mathrm{ox}}=-0.24 \mathrm{~V} ; E_{\text {red }}=-2.07 \mathrm{~V}$ for $9 \mathrm{Pt}$ ), which clearly reflects the $20 \pi$ isophlorin structures of these compounds [12]. Despite having an electrochemically oxidizable $\pi$ circuit, both 9Pd and 9Pt are chemically stable and resist aerobic oxidation under ambient conditions. This is a remarkable property endowed by the core-modification with phosphorus, because most of the isophlorins and their metal complexes reported so far are air sensitive. There are only small differences in the redox poten- 

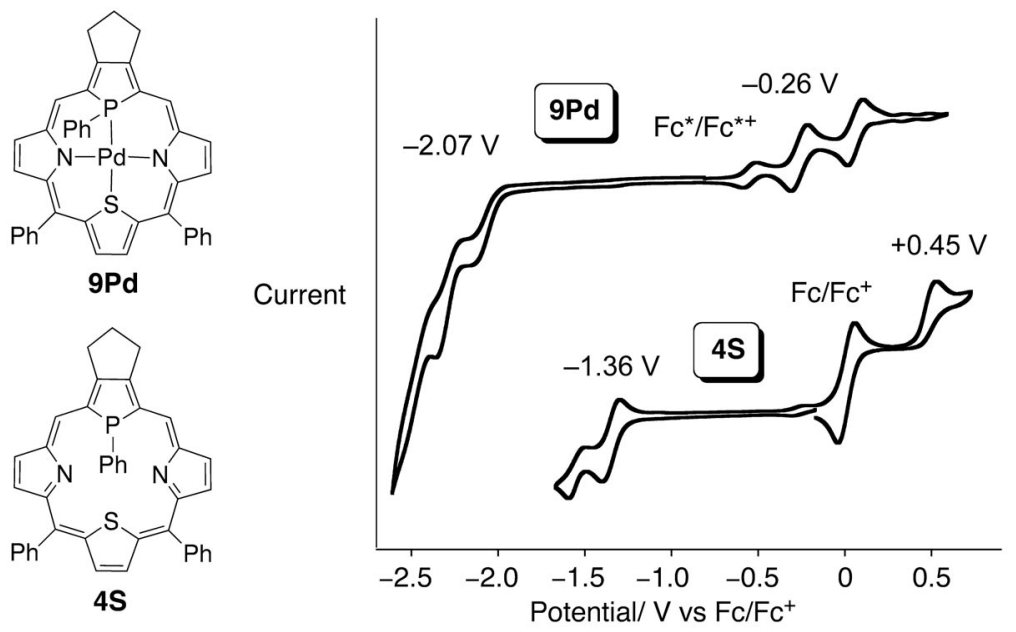

Fig. 4 Cyclic voltammograms of $4 \mathrm{~S}$ and $9 \mathbf{P d}$; in $\mathrm{CH}_{2} \mathrm{Cl}_{2}$ with $n \mathrm{Bu}_{4} \mathrm{NPF}_{6}$. $\mathrm{Fc}=$ ferrocene; $\mathrm{Fc} *=$ decamethylferrocene. The potentials listed are relative to $\mathrm{Fc} / \mathrm{Fc}^{+}$.

tials between 9Pd and 9Pt, suggesting that the central metal in 9M does not significantly alter the electronic character of the $\mathrm{P}, \mathrm{S}, \mathrm{N}_{2}$-isophlorin $\pi$ circuit [12].

\section{CONCLUSION}

Phosphole-containing $\mathrm{P}, \mathrm{X}, \mathrm{N}_{2}$-porphyrins are now accessible from a phosphatripyrrane and the corresponding 2,5-difunctionalized heteroles. Our recent studies have disclosed that the reactivity and coordination behavior of these hybrid porphyrins rely deeply on the combination of the core heteroatoms. In the P-oxidation, the $18 \pi \mathrm{P}, \mathrm{X}, \mathrm{N}_{2}$-porphyrins undergo $\pi$-reorganization to afford different types of unusual $\pi$-systems depending on $\mathrm{X}$. In the complexation, the $\mathrm{P}, \mathrm{N}_{3}$ free base binds rhodium at the core without changing the $\pi$-system to give the aromatic $18 \pi \mathrm{Rh}-\mathrm{P}, \mathrm{N}_{3}$ complex, whereas the $\mathrm{P}, \mathrm{S}, \mathrm{N}_{2}$ free base undergoes redox-coupled complexation with zero valent nickel, palladium, and platinum to afford the weakly antiaromatic $20 \pi \mathrm{M}-\mathrm{P}, \mathrm{S}, \mathrm{N}_{2}$ complexes. Notably, the latter result provides a conceptually new approach to construct chemically stable $20 \pi$ porphyrins (isophlorins) by the combined use of two methodologies, core modification and metal complexation. The observed structures, reactivities, and coordinating properties of the $\mathrm{P}, \mathrm{X}, \mathrm{N}_{2}$-porphyrins are undoubtedly produced by the phosphorus atom at the core. In this context, the phosphole-containing porphyrins are regarded as metal-affinitive macrocyclic $\pi$-systems and could be developed as new classes of metal sensors, sensitizers, and catalysts. Our next research projects, which include exploration of the coordination chemistry of phosphole-containing expanded porphyrins, are currently underway in our laboratory.

\section{ACKNOWLEDGMENTS}

We deeply thank our co-workers, Mr. Makoto Nakashima, Mr. Shinya Fujishige, Mr. Tooru Miyajima, and Prof. Haruyuki Nakano, for their contributions to the chemistry presented herein. This research was partially supported by the Grant-in-Aid from the Ministry of Education, Culture, Sports, Science and Technology of Japan (Nos. 19027030, 20036028, and 20038039) and the Sumitomo foundation. TN thanks a JSPS fellowship for young scientists. 


\section{REFERENCES}

1. See, for example: (a) M. J. Broadhurst, R. Grigg, A. W. Johnson. J. Chem. Soc. C 3681 (1971); (b) L. Latos-Grażyński. In The Porphyrin Handbook, Vol. 2, K. M. Kadish, K. M. Smith, R. Guilard (Eds.), Chap. 14, Academic Press, San Diego (2000); (c) H. Furuta, H. Maeda, A. Osuka. Chem. Commun. 1795 (2002); (d) T. K. Chandrashekar, S. Venkatraman. Acc. Chem. Res. 36, 676 (2003); (e) P. J. Chmielewski, L. Latos-Grażyński. Coord. Chem. Rev. 249, 2510 (2005); (f) I. Gupta, M. Ravikanth. Coord. Chem. Rev. 250, 468 (2006); (g) H. Maeda, H. Furuta. Pure Appl. Chem. 78, 29 (2006); (h) T. D. Lash. Eur. J. Org. Chem. 5461 (2007); (i) M. Pawlicki; L. Latos-Grażyński. Chem. Rec. 6, 64 (2006); (j) Y. Matano, H. Imahori. Acc. Chem. Res. 42, 1193 (2009).

2. See, for example: (a) F. Mathey. Chem. Rev. 88, 429 (1988); (b) F. Mathey. Angew. Chem., Int. Ed. 42, 1578 (2003); (c) M. Hissler, P. W. Dyer, R. Réau. Coord. Chem. Rev. 244, 1 (2003); (d) L. D. Quin. Curr. Org. Chem. 10, 43 (2006); (e) T. Baumgartner, R. Réau. Chem. Rev. 106, 4681 (2006); (f) T. Baumgartner, R. Réau. Chem. Rev. (Correction) 107, 303 (2007); (g) C. Lescop, M. Hissler. Tomorrow's Chem. Today 296 (2008); (h) Y. Matano, H. Imahori. Org. Biomol. Chem. (Perspective) 7, 1258 (2009).

3. D. Delaere, M. T. Nguyen. Chem. Phys. Lett. 376, 329 (2003).

4. Z. Duan, M. Clochard, B. Donnadieu, F. Mathey, F. S. Tham. Organometallics 26, 3617 (2007).

5. (a) Y. Matano, T. Miyajima, T. Nakabuchi, Y. Matsutani, H. Imahori. J. Org. Chem. 71, 5792 (2006); (b) Y. Matano, T. Miyajima, H. Imahori, Y. Kimura. J. Org. Chem. 72, 6200 (2007); (c) Y. Matano, M. Nakashima, H. Imahori. Angew. Chem., Int. Ed. 48, 4002 (2009).

6. P,X,N 2 -porphyrins $(X=S, N)$ : (a) Y. Matano, T. Nakabuchi, T. Miyajima, H. Imahori, H. Nakano. Org. Lett. 8, 5713 (2006); (b) Y. Matano, M. Nakashima, T. Nakabuchi, H. Imahori, S. Fujishige, H. Nakano. Org. Lett. 10, 553 (2008); (c) T. Nakabuchi, M. Nakashima, S. Fujishige, H. Nakano, Y. Matano, H. Imahori. J. Org. Chem. 75, 375 (2010).

7. $\mathrm{P}, \mathrm{X}, \mathrm{N}_{2}$-calixphyrins $(\mathrm{X}=\mathrm{S}, \mathrm{N}, \mathrm{O})$ : (a) Y. Matano, T. Miyajima, T. Nakabuchi, H. Imahori, N. Ochi, S. Sakaki. J. Am. Chem. Soc. 128, 11760 (2006); (b) Y. Matano, T. Miyajima, N. Ochi, T. Nakabuchi, M. Shiro, Y. Nakao, S. Sakaki, H. Imahori. J. Am. Chem. Soc. 130, 990 (2008); (c) Y. Matano, T. Miyajima, N. Ochi, T. Nakabuchi, M. Shiro, Y. Nakao, S. Sakaki, H. Imahori. J. Am. Chem. Soc. (Correction) 131, 14213 (2008); (d) Y. Matano, M. Fujita, T. Miyajima, H. Imahori. Phosphorus, Sulfur Silicon Relat. Elem. In press.

8. P,X, $\mathrm{N}_{2}$-calixpyrroles $(\mathrm{X}=\mathrm{S}, \mathrm{O})$ : (a) Y. Matano, T. Nakabuchi, T. Miyajima, H. Imahori. Organometallics 25, 3105 (2006); (b) T. Nakabuchi, Y. Matano, H. Imahori. Organometallics 27, 3142 (2008).

9. A. Ulman, J. Manassen. J. Am. Chem. Soc. 97, 6540 (1975).

10. P.-Y. Heo, C.-H. Lee. Bull. Korean Chem. Soc. 17, 515 (1996).

11. Y. Matano, T. Nakabuchi, M. Nakashima, H. Imahori. Unpublished results.

12. Y. Matano, T. Nakabuchi, S. Fujishige, H. Nakano, H. Imahori. J. Am. Chem. Soc. 130, 16446 (2008).

13. See, for example: (a) M. K. Cyrañski, T. M. Krygowski, M. Wisiorowski, N. J. R. van Eikema Hommes, P. von R. Schleyer. Angew. Chem., Int. Ed. 37, 177 (1998); (b) J. Juselius, D. Sundholm. Phys. Chem. Chem. Phys. 2, 2145 (2000); (c) H. Furuta, H. Maeda, A. Osuka. J. Org. Chem. 66, 8563 (2001); (d) E. Steiner, P. W. Fowler. ChemPhysChem 3, 114 (2002); (e) E. Steiner, A. Soncini, P. W. Fowler. Org. Biomol. Chem. 3, 4053 (2005); (f) P. Campomanes, M. I. Menendez, G. I. Cardenas-Jiron, T. L. Sordo. Phys. Chem. Chem. Phys. 9, 5644 (2007). 
14. For discussion about the relationship between aromaticity and structure of [ $4 n$ ]annulenes, see, for example: (a) J. A. Pople, K. G. Untch. J. Am. Chem. Soc. 88, 4811 (1966); (b) A. Minsky, A. Y. Meyer, M. Rabinovitz. Tetrahedron 41, 785 (1985); (c) E. Vogel. J. Heterocycl. Chem. 33, 1461 (1996); (d) H. S. Rzepa. Chem. Rev. 105, 3697 (2005); (e) Z. S. Yoon, A. Osuka, D. Kim. Nat. Chem. 1, 113 (2009).

15. M. Pohl, H. Schmickler, J. Lex, E. Vogel. Angew. Chem., Int. Ed. Engl. 30, 1693 (1991).

16. C. Liu, D.-M. Shen, Q.-Y. Chen. J. Am. Chem. Soc. 129, 5814 (2007).

17. J.-i. Setsune, K. Kashihara, K.-i. Wada, H. Shiozaki. Chem. Lett. 28, 847 (1999).

18. J. S. Reddy, V. G. Anand. J. Am. Chem. Soc. 130, 3718 (2008).

19. (a) J. A. Cissell, T. P. Vaid, A. L. Rheingold. J. Am. Chem. Soc. 127, 12212 (2005); (b) H.-e. Song, J. A. Cissell, T. P. Vaid, D. Holten. J. Phys. Chem. B 111, 2138 (2007); (c) J. A. Cissell, T. P. Vaid, G. P. A. Yap. J. Am. Chem. Soc. 129, 7841 (2007).

20. (a) A. Weiss, M. C. Hodgson, P. D. W. Boyd, W. Siebert, P. J. Brothers. Chem. Eur. J. 13, 5982 (2007); (b) P. J. Brothers. Chem. Commun. 2090 (2008).

21. M. Abe, D. G. Hilmey, C. E. Stilts, D. K. Sukumaran, M. R. Detty. Organometallics 21, 2986 (2002).

22. See, for example: (a) S. Shimizu, J.-Y. Shin, H. Furuta, R. Ismael, A. Osuka. Angew. Chem., Int. Ed. 42, 78 (2003); (b) Y. Yamamoto, A. Yamamoto, S.-y. Furuta, M. Horie, M. Kodama, W. Sato, K.-y. Akiba, S. Tsuzuki, T. Uchimaru, D. Hashizume, F. Iwasaki. J. Am. Chem. Soc. 127, 14540 (2005); (c) J. A. Cissell, T. P. Vaid, G. P. A. Yap. Org. Lett. 8, 2401 (2006). 